Network Working Group

Request for Comments: 35

Category: Informational
S. Crocker

UCLA

3 March 1970

\title{
Network Meeting
}

I expect to have the details of the new network protocol as outlined in NWG/RFC \#33 ready in two weeks. Some interest has been expressed in a live presentation, so we will host a network meeting on Tuesday, March 17, at UCLA at 9:00 a.m. To facilitate interaction, please limit attendance to one programmer from each site. It is also wise to leave the 18th open in case discussion continues.

The subject of the meeting will be a detailed presentation of the network protocol, suitable for implementing unless major flaws are discovered. Documentation will be available at the meeting and if not obsoleted by the meeting, will be sent out as NWG/RFC on March 20.

Please call Mrs. Charlotte LaRoche at (213) 825-2543 if you need help in making arrangements.

[ This RFC was put into machine readable form for entry ]

[ into the online RFC archives by Jochen Friedrich 4/97 ] 